\title{
Abysmal Laughter
}

\author{
StUart GRant
}

Laughing and crying are the responses to the failure of any complete dovetailing between the social and the genetic apriori ... an unbridgeable abyss remains (Heller 201).

\section{Preamble}

In early 2008, a mixture of performance studies and communications students, with limited general theoretical/philosophical background, and no knowledge of phenomenology or theories of comedy, were given six lectures by Agnes Heller on material from her book, Immortal Comedy, as part of an assessable unit of coursework. These students were offered assessment options of either writing essays, devising and performing short, annotated comic pieces, or participating in a group phenomenological project as a further assessment stream. About a third of the class chose to participate in the phenomenology group. This is a report on their work-its methods, its findings, and the possible avenues it opened for further investigation.

\section{The Questions}

As a result of her survey of the tradition of the study of comedy and laughter in Western philosophy and aesthetics, Heller makes two propositions: (1) Laughter is the instinct of reason (Heller 29); and (2) The comic and laughter spring from the tension arising from the abyss which opens as a result of the failed dovetailing of the genetic apriori and the social apriori (201). ${ }^{1}$ 
She derives these two propositions from an attempt to find consistencies in the dispersed field of comic practice, and in the theory which purports to explain it. These two apparently simple statements arise from and attempt to unify a field of paradox and often contradictory understandings. Our group discussions often returned to questions of whether and how our descriptions might shed light on these propositions.

Two further guiding questions were posed:

1. What is the meaning of laughter?

2. Why and how is funny funny?

Again, it quickly became apparent that these two questions, like Heller's two propositions, would not succumb to easy answers, but rather gave entry into a realm of hidden hermeneutic and ontological presuppositions, obscured further by an almost superstitious belief that asking the questions would destroy the very funniness and laughter to which they were addressed. There is nothing more ridiculous than being serious about comedy. I warned the class that we ventured into this project at the risk of never again being able to find anything spontaneously funny.

I decided to submit this article to this issue of this journal for three reasons. First, and most obviously, Heller's theory situates the eruption of laughter from a postulated primordial abyss, a gap, a failure, which opens at a preconscious level where a body with certain given genetic potentials attempts to reconcile itself with the pre-existent social structures into which it finds itself thrown. ${ }^{2}$ Second, as a phenomenological study, it aimed to clarify the hidden dimensions of an apparently universal, everyday, but misunderstood human phenomenon. And third, it was the result of a practical group phenomenological method with a well-defined tradition, claiming a verifiable and valuable route to the things themselves. 
However, the limited and preparatory nature of this phase of the project must be stressed. The main aim was to produce a set of starting points for further analysis. A full phenomenology of laughter and the comic requires a sustained investigation. Phenomena of comedy and laughter are so omnipresent in our everyday lives, yet so misunderstood, or more accurately, so widely tied up in understandings derived from unexamined misconceptions, that it is necessary to do a great deal of unlearning and unpacking as part of its preparation as a phenomenological study. Heller's ideas helped open the ground. They suggested redefinition and questioning of widely taken-for-granted assumptions, and provided hermeneutic tools to begin the clearing of those assumptions, making a relatively more presuppositionless approach possible. Or, more realistically, they provided a clearer, more conscious and controlled set of presuppositions from which to proceed.

In the thirteen weeks of this initial phase, it was necessary first to introduce the students to some basic phenomenological ideas and methods, attend a number of events and write reports on them, and finally to conduct group discussions. Consequently, the modest aim of this work was to use the theory to assist in the isolation of some obdurate prejudices and assumptions, and use these as taken-for-granted theoretical positions to be placed in suspension in a preliminary psychological-phenomenological reduction. A more in-depth study, based on the findings outlined here, and framed within a transcendental-phenomenological reduction, is currently underway and is expected to take at least another twelve months. ${ }^{3}$ 


\section{Theoretical Background}

\section{(a) Existing Theories}

But when we speak about the comic, we face a mess (Heller 5).

The study of comedy and laughter in the Western philosophical tradition has a long patchy history encompassing contributions from Aristotle to Quintilian to Kant to Schopenhauer to Hobbes to Baudelaire to Freud, Bergson and Bakhtin. The question of why, when, how, and at what we laugh has been studied as aesthetics, poetics, ethics, psychology, politics, physiology, anthropology and sociology.

In recent times there has been an explosion of work on the subject, motivated, in the main, by the inconclusiveness or partiality of the traditional theories. John Morreall has written a clutch of books on the subject; Simon Critchley (On Humour) takes a popular culture studies look at the field; Marcel Gutwirth (Laughing Matter) gives a wide-ranging, literary, textual analysis; Robert Provine (Laughter) has conducted an extensive and very useful empirical/psychological study; and Barry Sanders (Sudden Glory) concentrates on some political dimensions of humour. These textual, psychological, sociological, anthropological, aesthetic and philosophical perspectives all share an acknowledgement of the difficulty of the question. Some of them have tried to find a single unifying theory; others have admitted an essential irreconcilability and ineffability of the comic. All of them, in some way, contain inadequate differentiation between, on the one hand, laughter and the comic, and on the other hand, everyday laughter and laughter at aesthetic productions-novels, performances, films etc. It seems that the more effort is given to the attempt to break up the comic and laughter into categories, the more they escape these same categories. 
Agnes Heller's book, Immortal Comedy, enters this field. Beginning with an admission of the ultimate irreconcilability of comedy, she nevertheless ends up with something which looks a lot like a universal theory which holds across epochs and cultures, and which shows something essentially human in the what, why, when and how we do or do not laugh.

In one of her lectures, Heller gave us a breakdown of comic theories into three categories: 1) The Power Theory, according to which we laugh at the misfortunes of others, or those who do not fit in with our group. Plato, Aristotle and Hobbes are the main proponents here; 2) Incongruity Theory. Bergson draws a series of incongruities: between fluidity and rigidity, between the organic and the mechanical, between beauty and deformity, between spirituality and materiality, between meanings. Schopenhauer and Kant also contribute to the incongruity theory; 3) Relief Theory. The relief theory par excellence is from Freud: "Relief comes in and through the sudden event, the point, the punch line," in which "desires and erotic and aggressive wishes are satisfied by the laughter" (Freud, cited in Heller 134).

Through an elaboration of the connections, overlaps and boundaries of the definitions which frame these three categories, and through an attempt to question the universal human foundations of laughter and the comic, Heller opens an enquiry which offers up an encompassing theory, which, she contends, accounts for all manifestations of these phenomena.

Because this whole study took place in the context of a course based on Heller's theory, and used that theory as a theme in an interpretive phenomenology aimed at revealing something of both the phenomena of laughter and the comic, and the theory itself, it is necessary to briefly outline the ground on which the theory took shape. 


\section{(b) Heller's Solution}

The Heterogeneity of the Comic: Heller suggests that the comic is a family with many members; that parody, satire, irony, slapstick, the grotesque and all the other manifestations of the comic share a family resemblance. Comedy exists in our everyday lives: as entertainment, in jokes, in mistakes, as the absurdity of life itself. It can be physical, intellectual, verbal, spoken, written, thought, perceived, voluntary, involuntary, a story, a game. Comedy is, in short, "entirely, absolutely, hopelessly heterogeneous" (6). Consequently, she eschews the project of finding a common essence which all instances of the comic might share, and instead prefers an approach which seeks to "divide and grasp the comic in general" (6). The heterogeneity of comedy demands a hermeneutic rather than an ontological approach. This led to the conclusion that our group needed to ask not "what is the essence of laughter?" but rather "what is the meaning of laughter?"

The Abyss and the Failure of Dovetailing: Heller's second observation begins with the assertion that comedy is a ubiquitous human phenomenon. All humans laugh—from snide snicker to polite chuckle to hilarious uproar-and this apparent universality both demands and allows for a particular type of study. For this, Heller turns to the language of the philosophical anthropology of Helmuth Plessner, who, in his book, Laughing and Crying, asks the question of "what it is like to live in, with, and as a human body" (Plessner, cited in Prusak 43).

Heller's enquiry is cast in terms of a specific definition of "the thrownness of Dasein in the world" (Heller 21). She understands thrownness as a meeting of a genetic/instinctive apriori with a social/cultural apriori. Simply put, "every person is born with an entirely unique genetic code ... prior to all experiencing ... an unrepeatable singularity" (21). This is the genetic apriori. But this newborn individual is thrown into a "social space, [a] culture ... entirely external ... and prior 
to all experience" (21). The genetic necessities and the social contingencies need to be reconciled. This process is continual and never entirely successful. Heller appropriates the term "abyss" from another philosophical anthropologist, Arnold Gehlen, for whom the human being remains always "incomplete" and "world-open" (Gehlen 76). According to Heller, laughter and the comic emerge from this abyss. "In my view, both laughing and crying are the elementary answers to Dasein, for they are triggered by the experience of the hiatus, that gap or abyss" (Heller 22). From the point of view of contemporary phenomenology it is possible to understand this abyss as an embodied tension, an unresolvedness which builds with experiences of expectation and discomfort and which attains release in laughter and the comic. This is a primary impetus to phenomenological interest-the ways in which preconscious, passive conditions manifest in an enigmatic, uncontrolled experience.

With this, the task of our group became to try to bring back the moment of the experience of this gap, to make it available for reflection. If laughter was to be understood as a bodily eruption/release of a tension created by hidden fundamental structures not normally available to conscious awareness, then it would require a phenomenology to thematize these structures.

The Instinct of Reason: This is by far Heller's most difficult concept in connection with the phenomenon of laughter. She begins with the difference between laughing and crying. Crying is emotional, solitary and empathetic. It is a despair, a mourning in the presence of the genetic/social abyss. Our genetic need to belong is thwarted. We are cut off from others in our social group. Crying is therapeutic. After the solitude of crying, we are ready to return to the company of others. By way of contrast, she contends that laughter is social and rational. We always laugh with others at something. And primarily, "laughter is judgmental; with it we pass a 
judgment ... there is no empathy in laughter" $(25) .{ }^{4}$ In laughing at someone or something we pass a rational judgment and assign a value. In this way, laughter becomes a source of belonging and identity: "For if we participate in a community of merrymakers, laughter itself becomes a value; it becomes an identity-constituting, cultural, and social value" (26).

However, although laughter is rational and social, it erupts, in what Heller calls its "primary" manifestation, as spontaneous outburst, beyond our control. "The body is entirely shaken, the facial expression gets distorted, and inarticulate noises are made" (19). Also, like crying, it is often accompanied by uncontrollable bodily secretions. As "non-voluntary expressions," laughing and crying are related to the "family of affects," the "functionally rational" instinctive remnants-most importantly to fear, anger, shame and disgust (19). We blush with shame, we tremble with rage, we shudder and are nauseated with disgust, we shake with laughter, we gasp uncontrollably in sobbing.

It should be noted that in our study we found that overwhelming outbursts of laughter are rare, and that laughter, more often than not, contains varying degrees of will, employed in service of some social effect. But nevertheless, the actual utterance of the laugh, and the value judgment it expresses are not thought through step-by-step in a considered manner, but occur immediately, in all but the most forced instances, in response to a given situation.

So, to put it very simply, laughter is, in Heller's thesis, somehow both rational and instinctive; an unthought wordless expression of the experience of a judgment. She announces: "Now I advance the result of my entire inquiry: it is laughter that is the instinct of reason" (29).

This is a very difficult concept to understand. The seemingly simple combination of the terms instinct and reason gestures beyond mere paradox. It suggests that the instinctive ground of the possibility of rational, logical thought can be directly experienced as laughter. This 
presupposes an experiential structure for which traditional ideas of rationality vs. instinct, will vs. reflex, judgment and reason vs. spontaneity, consciousness vs. unconsciousness, and individual vs. social have been unable to give satisfactory account. It also suggests preconscious, passive processes which demand phenomenological elucidation. The concept of the instinct of reason is crucial to this study. It allowed avenues of approach and gave substantial direction to our enquiry. As will be revealed later, the most essential moment of the comic- "the getting of the joke"- became clarified only through the application of this concept.

Heller elaborates her theory in far more detail and includes different species of reason and a multitude of examples, but still, like the work of her predecessors, it is entirely theoretical/textual. Without a study of the phenomenon itself, as it occurs and manifests in the world, it remains ungrounded. A phenomenological enquiry was necessary to get at the experience of the instinct of reason insofar as it occurs as the moment of the comic, define it, and bring it back for reflection.

\section{The Method-Group Phenomenology}

The method for the research was an adaptation of my doctoral work. I will not detail the process here. The full description and genealogy of the method can be found in two articles of mine: "Practical Intersubjectivity" and "Immanent Description and Writing From ...". Briefly, the methodology was derived from a tradition inspired by the phenomenological work of Herbert Spiegelberg, David Seamon and Amadeo Giorgi, as well as the 1996 conference, "Back to The Things Themselves," at Southern Illinois University Carbondale (see also Steinbock, Casey). 
The primary advantage of the group method is attunement of the various viewpoints, experiences and opinions of the participants. Certain themes and commonalities emerge consistently in the descriptions of different participants. Discussion aimed at clarifying differences often reveals unexpected common ground. According to Spiegelberg,

[c]ooperative phenomenology is not merely a matter of exchanging views, of "swapping" reports, as it has been called, or even of registering and, as far as possible, understanding one another's different perspectives. Such an outcome need not be the "end of the story," it can be the beginning of a new one, the attempt to attune dissonances (33).

Spiegelberg's instructions are clear. Argumentation is avoided. When there are differences, their sources are sought with an aim to come to common understandings. Precise amounts of time are allotted to each participant. Positions are not defended, tastes are not justified; the aim is clarity.

The students were given a brief history of the concept of intentionality, from Cartesian certainty, to Kantian transcendentalism, to Husserl's adaptation of the scholastic term redefined by Brentano, to Heidegger's Being-in-the-world, Merleau-Ponty's flesh, and Levinasian enjoyment. They were instructed that we were there to study the intentional structure of when, how, with whom and at what we laugh.

The second theme of the theoretical training was the method of the reduction and bracketing. The students were taught a simplified version extracted from the various drafts of Husserl's Encyclopaedia Britannica article, from 1927, which lays out the difference between a first-stage worldly-psychological level of reduction, in which apparent phenomena are described, and a subsequent, more transcendental-ontological level of enquiry at which the essences clarified from the first level are further reduced. This study remained at the more worldly level. 
The training entailed very specific definitions of the natural attitude and the phenomenological attitude. ${ }^{5}$ In our preliminary attuning discussions, we realized that the primary activity we perform when attending a comedy show or any other type of live performance is judging whether we liked it or not, whether we found it funny or not, whether it accorded with our values of what we considered a good show, whether we enjoyed it. For the purposes of this exercise, it was deemed that this is the unreflective, natural attitude of attending to a comic performance. Consequently, the main theoretical position to be bracketed in the reduction was whether we were amused or entertained, thus allowing the taking up of a phenomenological attitude in which it was possible to describe the structures and mechanisms used to generate the humour. However, we were vigilantly aware of Merleau-Ponty's dictum that "the most important lesson which the reduction teaches us is the impossibility of a complete reduction" (MerleauPonty xiv). We knew we could not exist in an entirely presuppositionless void, so we allowed ourselves, in the experience of being in front of the comedic object with our natural attitude held in suspension, to selectively bring in the theories of comedy to help interpret that experience. It should be emphasized that conversely, the theories of comedy were being put to question by our descriptions, rather than being used as frameworks into which to fit the experience. Part of the aim of this first stage of the project was to bring the extant theories into the phenomenological description in order to eventually supersede and dispense with them through the production of more phenomenologically-derived categories. The emergence of the theme of the temporality of expectation, detailed below, in the discussion of Frank Woodley's Possessed, demonstrates how this worked. 
Some students found the task difficult. They were instructed to examine the audience, their relationships to other audience members, the movements of laughter through the audience, their own laughter, and its occasions and relationships to other events. Some took notes. Some expressed a fear that it would prevent their normal enjoyment of the show, but were surprised to find that, instead, it opened up and broadened the experience, providing extra enjoyment rather than destroying the naive apprehension of the performance.

\section{The Shows}

\section{(a) Frank Woodley's Possessed}

Possessed was a one-man show performed by Frank Woodley, a highly skilled and popular comedian. It was a well-resourced and budgeted show with an elaborate set, a large production team, writers and director. It was staged at The Comedy Theatre, built in 1928, a large, prestigious venue with a capacity of one thousand.

The play tells the story of a man named Louis who has never left his room. He lives alone, with only a rat, of which he is terrified, for company. His only human contact is in phone calls to his demented mother. He makes models of old wooden ships for a hobby. He becomes possessed by the spirit of an Irish woman who had died in the shipwreck of the original vessel of one of the models he is making.

The comedy derived from Woodley's slapstick skill in negotiating the staircase, furniture, cupboards, ladders, doors and other obstacles and traps in the apartment, and in his physical ability to embody two characters at once. It was a slick, well-produced and brilliantly acted performance which ran with clockwork precision. The laughter was thick and constant. 
An example from one of our descriptions is indicative of how our work unfolded:

I also noticed that the audience was frequently anticipating jokes. For example, two thirds of the way through the production, Frank picked up his guitar from the corner of the room. As soon as this occurred there were noises of appreciation that swept through the audience. From this, it became clear that the majority of the audience members were familiar with Frank's previous work and were aware that he was not only a talented comedian, but also gifted at musical comedy. It was also interesting to find that after the fisherman had been established in the first scene, when he next walked onto the stage, the audience laughed and cackled before anything had actually happened. Because we had already met the fisherman, and had laughed heartily at his initial jokes, as soon as he walked back onto the stage we were expecting to be entertained.

Another member of the group noted that:

I found a few times during the performance that I was laughing even though I knew what was going to happen next. For example, when Phoebe noticed the Vegemite, ${ }^{6}$ I knew that because she was not from Australia she would think it was terrible. And I was correct, at least initially. When Louis's dad was singing the "love song" on his guitar, I knew exactly what the lyrics were going to be, as I had seen him on the Comedy Gala on Channel 10. I still laughed though. I noticed that there was a time when Louis used the furniture and poles in his house to get to the toilet. There was nothing funny about his journey, but the audience still laughed. I put this down to the fact that previous to this attempt, Louis had tried and failed to use the furniture to get up to the same area. We laughed because of a prior memory we had of when the situation was meant to be funny.

I cite these two examples to indicate how attunement worked in the process. We had come across theories which talked about the element of surprise in comedy. However, many of us found that we were laughing more at what we expected than at the surprises. This happened so frequently that the figure of expectation - which none of the theories we had covered had dealt with specifically, but all of which, on subsequent examination, appeared to presuppose to some degree-emerged as an essential moment of the comic.

This provided us with the phenomenological category of the temporality of expectation as a theme for further investigation. Other themes, similarly reduced, are detailed below in the section "Findings." 


\section{(b) Blank-The Musical}

Blank was a very loose, improvised performance in which a troupe of six actors and a pianist asked the audience for a word, from which they devised an impromptu piece of musical theatre. On the night we attended, the audience provided the word "chilli." The players improvised a story of South American drug barons and junk food restaurateurs on personal journeys of self-discovery.

The theatre, a university auditorium with several hundred seats, was sparsely populated. The show limped from absurdity to failure, with rare flashes of brilliance. The small audience gave polite laughter, mostly sympathetic and encouraging rather than entertained and amused. Towards the end of the performance, the cast members deteriorated into laughing at the absurdity of their own bad dramatic and musical choices, as well as their poor execution.

The looseness and multiple failed jokes of the show revealed types of laughter other than a simple stimulus-response structure of "joke told—get joke—laugh/don't laugh."

Students found attunement in their experiences and descriptions of the more complex intentionality of their own and each others' laughter:

I thought a lot of my laughter was based on the social need to make the comedic event go smoothly, but your accounts of how we laugh down in recognition of their failure has led me to believe that maybe I am laughing more at the performers than with them. Did you find you were laughing with them as much as at them? Or was it the opposite?

Feeling out of place when the others laughed made me force out a laugh even if I did not find it particularly funny. Did you find yourself doing this at any point? Were Gaby and Semi laughing during any of these jokes? If so, did you find yourself laughing when they did, perhaps in an attempt to remain within your social group?

You spoke about how we recounted the stories told in Blank and laughed at the parts that failed to make us laugh at the time; do you think this was due to a need for release? If the actors had set something up as "a joke" but it failed to make us laugh, do you think that perhaps we felt a need to release the tension when we were talking about it that had been built up on the night, but never properly released? 
And another participant:

I am really interested in the comment about being on the actors' side and wanting them to succeed in making [us] laugh. Quite a few people have made this comment, and I too felt that going into Blank I wanted it to be funny, I wanted to enjoy it. How much influence do you think this expectation or want/need has on our experience of the show? Do you think we laugh more because we think it should be funny or because we have such a need to laugh? When I think back, there were many things in Blank that weren't very funny but I still laughed at. Was this merely to relieve the mounting tension in regards to needing to laugh? Why did [we] want them to succeed so much? How would we feel if they didn't? We laughed in Blank so the actors wouldn't be embarrassed or we wouldn't be for them. Is laughter merely a protection device for us?

All the participants found a complex variety of intentional positions, directions and motivations in the laughter elicited by this show. The project of something like a typology or full intentional analysis of laughter was put on the agenda for further study.

\section{(c) The Laughter Club}

We also attended a Laughter Club. People attend a weekly meeting where they perform a series of exercises which they claim "improves the physical, mental, emotional, spiritual and social health of individuals, workplaces, and society" ("Laughter Clubs").

Each exercise consists of a specific bodily movement accompanied by a forced mechanical laughing sound. They are named for the movement: "the lawnmower laugh," "the waking up laugh," "the windmill laugh." The instructions are given with physio-chemical explanations of what is happening in the brain during laughter. The exercises are interspersed with interludes where participants stand in a circle, clapping the hands of those on either side, making enforced eye contact around the circle. 
There were four members in the group we attended. They identified themselves as "laughers," made jokes about laughing, puns and plays on the word "laughter," and mildly derogatory comments about people who did not have enough laughter in their lives.

Questions raised by the laughter club reports led to consideration of social and physical catharsis.

Although I don't like admitting to it, I did find that the most important cause for my laughter came from the group members themselves. Arriving at the club I formed a strong judgement and opinion about the participants, which didn't change over the course of the session. There were a total of four laughing club members, (one arrived half an hour later) and they all seemed somewhat socially inept. The small size of the group also further enhanced my downward judgement, as it clearly was not a popular club. As we have found in our comedy classes, laughter is always at something and with someone.

I found that when my genuine laughter took over my mechanical laughter, it was also because I was laughing at myself, in a bizarre situation which I was unfamiliar with. I found that this laughter could be looked at ... as a release of tension. I was a little tense arriving to the session after getting lost, frustrated at my lack of sleep and also a bit disappointed that no one in the comedy class was able to come. Added to this tension, was the whole club itself. Participating in ridiculous exercises, with ridiculous people, in a public place ... It was no wonder that I began naturally laughing after the first exercise-I clearly needed a release.

In reflection I have had a number of new thoughts about the club. What was fascinating was that throughout the whole session, every participant laughed on a very similar scale. No one ever reached a point of hysterical laughter. And every member was laughing at similar times. It would be interesting to assess what would have happened if one member of the group either stopped laughing altogether, or reached a point of hysterical laughter. My prediction would be that the remaining members of the group would follow suit. Once one person had started laughing, either mechanically or organically, it didn't take long at all for the rest of the group to join in ... I was often quite surprised at when my genuine, organic laughter kicked in, as it always took me by surprise. It was never a conscious decision and was always involuntary.

There is a difficult question which arises here concerning the links between the social/identity aspects of laughter and the personal/physical dimension. Some students are currently examining this problem, describing and interpreting popular comedy TV shows in light of Aristotle's cathartic return to the mean, and Kant's idea of laughter as "fruition of the state of 
well-being arising from the restoration of the equilibrium of the various vital forces within us" (Kant, sec. 29).

\section{(d) "Knock-Knock"}

A description of a YouTube clip called "Knock-knock" reveals more about another aspect

of a cathartic function in comedy. We had observed that, particularly in stand-up comedy, comedians performed a kind of social boundary rider function, exploring the limits of moral and social acceptability, saying things that the audience thought but did not feel permission to say. This was revealed by discussions stemming from descriptions of this clip. ${ }^{7}$

This is a great example because it is so specific to our historical and cultural moment, and so complex theoretically. It starts with a knock-knock joke. A knock-knock is a child's joke, a very innocuous and hackneyed form. We all know them. We come to them with certain expectations. They are usually about childish and playful puns. However, we do have an experience of "adultish" (or at least adolescent) knock-knocks where the name might be very long and the answer is often pointless and ridiculous. There are also knock-knocks which derive their humour from breaking the usual form or pattern of the joke. This piece plays with those more mature forms of the knock-knock, so it brings a certain complexity of understanding with it. The complexity here is the history we all carry of this type of joke and its different forms and variations. In this instance, when the answer to the "Who's there?" is "I'm thinking of killing myself," we laugh at the fact that in the past we laughed at mutations of this form of joke and this mutation mutates the other different mutations we have laughed at (when we were 4, 10, or 16 years old). ${ }^{8}$ In this joke, this world of the story of the development of our childish humour is placed next to some of the most serious issues that our society deals with today. The suicide theme is as serious as it gets, so therefore it's a good source of laughs. It gives us the ultimate existential joke-our own death. The character telling the joke talks about the empty meaninglessness of his life. In the familiar context of a knock-knock joke, the incongruity is very effective. When the protagonist talks about how he was molested as a child, there is an eerie resonance in placing this alongside the child's joke form. The two worlds are placed side by side. Each has its own connotative resonances. Both sides have to do with childhood, but are very different in their timbre and tone. The discordant clashing of these resonances gives rise to laughter.

The rhythm and structure of the piece is another source of humour. Each time the joke teller gets serious, it is longer and more serious than the previous occasion. The phone ringing adds another note of tension. Neither the straight man in the clip nor the audience 
knows whether he is serious or not. He builds us into thinking he is, then he lets us off with "it's just a joke." He does this a number of times. Each repetition accumulates tension. The eventual suicide is both a perfectly logical consequence and a letdown. And it leaves us with the ultimate joke, death, which is also the ultimate seriousness. The rhythm of this play of seriousness and humour is very measured.

The shooting style of the clip also makes humour in its own right. It parodies the ever closer close-ups which are used in sentimental movies and soap operas to create increasing drama and tension. The lighting gets spookier with more shadows.

This complex use of incongruities, in content, in the structure of the narrative, in the play of expectations of the form of the joke itself, in the technical means of telling the story, in the straight man and stooge, in the serious and the funny, in the play of who knows what (the two characters, the audience), in the uncertainty, in the tension and release, makes for a rich comic brew which sustains its effect continuously.

Again, these descriptions, guided by Heller's redefining but problematic and paradoxical theory, point to dimensions of the workings of comedy more profound than the accounts given in either the traditional theories of the comic, or the taken-for-granted everyday understandings of the phenomenon. It became very clear at the end of this phase at the work that we were only at the beginning of a much larger and weightier enquiry.

\section{Findings}

Working with phenomenological novices, in the necessarily short timeframe and scope of this phase of the project, necessitated an awareness of the limits of what we were capable of producing. As a worldly-psychological study it was always implicit that we were seeking some fundamental grounds which might be used for a subsequent, more fundamental transcendental analysis. In this aim, the two main successes of the study were: first, the experiential location of Heller's "instinct of the rational" as the moment of "getting the joke," and making it available for further study; and second, the experiential location of the apparently paradoxical structure of relations constituting a phenomenon. Laughter is always a judgment (and therefore always 
explicable after the fact in rational/logical/causative terms) and yet arises and operates, in multiple different ways, as a response to multiple different situations, through the evocation of a fundamental ontological human condition emerging in a spasm of the respiratory and vocal apparatus.

Some components of this structure became consistent themes in our discussions and provided operators for further examination in current ongoing enquiries. ${ }^{9}$ At present the following operators are being examined:

At/With Intentionality. In phenomenological terms, the questions of the sociality of laughter and Hobbes' power theory became questions of intentionality. Who knows what? Who is laughing with whom at what or whom else? How does this lead to intersubjective belonging and identity? Whom or what is the performer inviting the audience to laugh at?

Students described specific instances of groups laughing down at others to reinforce their own belonging and identity. Stand-up comedy revealed an intentional structure of a comedian drawing audiences to laugh together at specific groups or individuals or themselves, or at others in the audience. It proved difficult to find any humour in which this dual intentionality was not at play.

Others interpreted this through the concept of the failed dovetailing of the genetic and social aprioris. The laughter that erupts between the members of a group crackles across the tension of the abyss between the genetic and the social, forging and sustaining belonging through the shared experience of the pleasant bodily affects of the laughter. The description of the intersubjectivity of laughter has been taken up by the current working group as a detailed and exhaustive intentional analysis of laughter. 
"Genuine" Laughter. This was one of the primary questions which emerged from the study. Heller writes of laughter which erupts uncontrollably, shakes the whole body and prevents speech. However, the group noticed that this was a rare occurrence in our descriptions. The laughter we experienced was always modulated by degrees of spontaneity, from the absolutely forced exercises of the laughter club; to the short burst of nervous laughter which sometimes escapes unconsciously at the end of sentences; to polite laughter at the unfunny jokes of our boss or our friends to make them feel comfortable, or to show fear; to the encouraging laughter for the performers which we described in the audience of Blank: The Musical; to laughter which shows our peers that we "get the joke"; to uncontrollable giggling. In each of these manifestations, there was found to be lesser or greater degrees of voluntary motivation.

It became apparent that the terms "authentic" or "genuine" laughter were inadequate to the phenomena we were experiencing. Two questions then arose. First, if the terms were descriptively inaccurate, then how should we talk about what we were experiencing? And second, what were we actually experiencing?

This became particularly clear in the premeditated, mechanical exercises of the laughter club, with the assertion that they were laughing at nothing. With our phenomenological presupposition of the at/with intentionality of laughter, we had to assume that they were either laughing at something of which they were unaware, or that what they were doing was not laughter. Is laughter a particular spasmodic activation of diaphragm and vocal apparatus, or is it something more? If it is something more, what is that something? Our phenomenological descriptions showed that the genuineness in "genuine laughter" required more accurate terms for its account. 
Those of us who attended the laughter club experienced points at which we felt a beingtaken-over or being-carried-by the originally mechanically initiated laughter. We noted that at these times there was a sense of laughing at something which came into play. When we had our intentional object, the laughter took us instead of us forcing it. In this case we were laughing at ourselves, nervously, with a sense of the ridiculousness of what we were doing, laughing out loud in a public park with five strangers; and also at the members of the club for their need to participate in this activity.

Some students suggested the need to make a typology of laughter. One of the types of laugh that came up for categorization was something people were calling "silent laughter." Upon request for clarification, it was revealed that this expression referred to a state where we "got" the joke, but didn't experience contraction of the diaphragm or vibration of the vocal chords. The question became: If this is a type of laughter, what does it share with other, physically manifested types of laughter? What sort of a thing is this, "getting the joke?"

After some discussion, we isolated a common moment in all our descriptions; a brief moment almost like the flick of a switch, when we "got the joke." This event was not an experience in the sense of a reflective awareness in its own right; we did not consciously elaborate an argument to ourselves about why we found something funny, but rather, either erupted in laughter or didn't. Nevertheless, upon reflection in our phenomenological process, we found that it was always a judgment, which was always based in a logical process of some sort. There was always a setup and a payoff, always an incongruity, an absurdity or a logical inconsistency. But the judgment happened so fast that it could only be broken down and explained after the fact. However, it was found to be present whenever an experience of the 
comic occurred. Whether it was a bad joke at which we laughed politely, or groaned, or ignored, or decided it wasn't funny, or a raucous giggling fit, or a standup punchline, an ironic parable, a slapstick mishap, or the recognition of a subtle sardonic raising of the eyelid-in each of these cases, there was this experience of the comic moment: the "getting it."

Because this moment happens so fast, unconsciously, yet is always found in retrospect to be a judgment, we agreed that this moment was Heller's instinct of the rational, crackling like an electric charge across the abyss between the two aprioris. The laughter itself is more or less spontaneous, occurs or does not, but the "getting of the joke" is always there in every comedic instance. If there is no "getting it," there is no comedy. This was perhaps the most important discovery of our research, and it arose directly from discussions of our descriptions.

Speed and Timing. Taking into account this discovery, it was possible to begin a line of questioning which replaced the question of authenticity or genuineness with one of speed and timing, notably expectation. The literature was full of references to suddenness. Hobbes' "sudden glory," Kant's moment when "the understanding, missing what it expected, suddenly lets go its hold" (sec. 54), Freud's "sudden burst" (Freud 96), Heller's observation that "suddenness ... is the condition of the joke effect" (Heller 135), all point to the importance of and need to explore the temporality of the comic. Our descriptions concurred. The common feature, or as Heller puts it, "the condition" of all comic occurrences, is the speed at which they happen.

This question of temporality, while insufficiently investigated because it arose at the end of our short period of research, received further attention later in the course when we were doing practical work on the performance of comedy. We experimented with different timings of scripts and delivery of jokes. We discovered that skilful comedians manipulate infinitesimal differences 
of timing; they are artists whose materials are judgments worked at the speed of instinct. Slow, drawn-out build-ups, measured repetitions, momentary pauses and sudden paradoxes are all tools in the temporal art of the comic.

We are currently conducting detailed temporal analyses of the play of expectation, repetition and surprise in comedy, to discover how we experience time in comedy. These infinitesimal differences of speed cannot be measured in units of minutes and seconds. By the time the experience of the instinct of the rational is reported, it is gone. Possible questions may be: What temporal patterns are laid out for us by the comedian? What are the rhythms, the gaps, the disjunctures, flows and durations of the comic? What delays or anticipations are at play?

Logic of Pairing. Around the same point in the progress of the research, Peter Murphy, the coordinator of the course, gave us a lecture on the role of pairs in comedy. He drew our attention to the frequency of figures such as stooge/straight man, mistaken identity, double entendre, conflicting narratives, parent/child, husband/wife, expectation/surprise, meaning/nonsense, organic/mechanical and other comic pairs.

By this stage in the process, our descriptions were calling the original theoretical ground into question. It became apparent that this logic of pairing was occurring consistently throughout the different theories and in our experiences, but in different ways and at different levels. For example, the incongruity theory, in its essence, is about mismatched pairs. These were everywhere in our examples. The tension and release of the relief theory was about the pair of the build-up and the punchline, the expectation and the surprise. The power theory is about those who know and those who don't; those who belong and those who don't. During this discussion, one of the students complained that we seemed to be arbitrarily attempting to fit the phenomena 
to the theories. At worst, we felt as though we were stumbling around in the dark with a torchlight looking for evidence of the theories in our examples. Some of our attempts seemed particularly implausible. However, in the discussions of our descriptions we found that in all forms of comedy, in a variety of different ways-formally, structurally, in content, in the performance-there was always at least one pair at work, and the more different levels at which pairs occurred, the richer, more long-lasting and resonant the comic experience. The description of the knock-knock joke above bears out this role of complexity in comedy.

One of Peter Murphy's examples led to a significant discovery. We were at a stage of discussing comic pairs we had found in our descriptions to see if our findings could shed any light on Heller's idea of the two aprioris. Peter gave us an example from a real world situation of a maintenance $\log$ in which airline pilots and ground maintenance staff communicated with each other about faults and problems with the aircraft. A tradition of humorous exchange had developed between the two sides. Among the entries was one in which the pilot had written, "scratching noise in cockpit like a mouse running around." The ground staff fixed the fault and replied, "cat installed."

This simple exchange, in the context of our attempt at understanding the theory of the two aprioris, led to a whole new avenue of enquiry. Something about the simple two-word term "cat installed" triggered a new direction. This expression is funny partly because it continues the pilot's playful description of a serious situation, and partly because cats, as living things, don't get installed. But the working of the two words suggests another level of effect entirely. The word "cat" has a certain connotative ambit. It suggests litheness, fluidity, alertness, stealth, sleekness, hypersensitivity. The word "installed" connotes machines, fitting together, coldness, efficiency. The sounds, movements and colours evoked by these words have very different 
resonance in our bodies and in the world. They suggest very different modes of being, of which we have a tangible sensual experience. It seemed that the evocative resonance of the words was working at a level which would require a poetics to understand. It revealed a dimension of the experience of the genetic/social abyss which we hadn't considered before. All of these different manifestations of pairs, at the different levels of form, content and structure, working at the speed of instinct, operated, in relation to the abyss, through a kind of poetic resonance. Although a judgment can be found after the fact, there is no logical working through, no decision making process. It appeared that the comic is a judgment which emerges from the tension of the genetic/social abyss through processes of evocation and resonance. The comic, though always related to rationality, is so elusive to pin down and understand, precisely because it appears to erupt without conscious decision-making. The comic evokes the abyss. It is more akin to the poetic image in the way it emerges, moves, is experienced and affects us. It seemed productive to ask the question of what a poetics of comedy might look like. The logic of pairing provides the shape, the outline, gap or opening, but it will require more basic phenomenological description and analysis to give a fuller understanding of the details of the movements and experiences within this structure.

Comic Catharsis. Despite Heller's belief that laughter and the comic are not functionally rational, that is, that they are not remnants of an instinctive means to an end in survival, our descriptions often referred to concrete salubrious bodily and social effects. We asked whether there is a case to be made to support something like a comedic analogue of Aristotelian catharsis. The laughter club provided some clues to where a future investigation into these areas might proceed. 
The laughter club promotional material explicitly promises improvement in "the physical, mental, emotional, spiritual and social health of individuals, workplaces, and society" ("Laughter Clubs"). If the claim is true, then their taking laughter outside of its usual everyday and entertainment environments might be seen as a laboratory where its power exists in a pure and isolated form.

The exercises we performed involved close physical activities, mutual touch and forced eye contact. In light of our presupposition of the primary social function of laughter, it seemed clear that this was some kind of remedial socializing; an intensive kind of foregrounding of laughter's role in the physical mechanics of intimate belonging and identity structures which hold people together in any type of family, group, organization or club.

So whether or not the initial impulse to laugh is "genuine," it is as if the body inclines towards laughter. Whether as the result of a willed decision to stimulate the organs as in the laughter club, or whether the stimulus comes from a joke or accidental comic event in the outside world, the emotional/physical tension and relief in the body, and in the timing of the joke, appear to be restorative, both personally and socially. Proposed detailed embodied descriptions will be necessary to explicate this phenomenon more clearly.

This thesis of a comic catharsis, both physical and social, also requires consideration of the role of the comedian as social boundary rider-one who pushes the acceptable limits of what might or might not be said, through skilfully-timed, delicate, acceptable transgressions. Stand-up comedy lives on the borders of taboo areas in interpersonal and broader social relationships. People who generally live within the moral norms of their society will go to watch comedians who say things that they themselves would never feel permitted to say about topics which they would never broach in conversation with their friends, workmates and family. This is a kind of 
direct access to the abyss between the genetic and the social, overtly testing the boundaries, gaps and tensions there. Topics of sex, personal relationships, race, language, politics, religion, ethics and morality, which comedians satirize, reveal, and mock are issues that arise specifically as attempts at dovetailing the genetic and the social. The best comedians seem to have the stomach to stand in the tension of the abyss, to find its moments, and to hold it and bear the responsibility of showing it to those who live within it.

Comment. Further research into these categories, still clearly guided by the impetus of Heller's work, and illuminated further by this process of considering the phenomena as manifestations of an "in-between" is, we believe, continuing to reveal genuine new understandings of the comic and laughter. The import of Heller here is demonstrated by the comments of a reviewer of this article, who asks "whether laughter is an unconscious logical (rational) judgment or partakes instead in a poetic, evocative form of meaning?"10 The concept of the instinct of reason and the description of the moment of "getting the joke" tells us that it is a complex structure entailing both. This "both" is the nub of the problem.

It has also been suggested that the concept of the abyss with which we are working needs further definition. The concept of the instinct of reason seems to me, in its apparent essential paradox, to be self-evidently abysmal. The reviewer's demand that laughter be either rational/logical or evocative/poetic misunderstands the point. It is both. And this "both" is Heller's abyss, Gehlen's unfinishedness; the gap between the genetic and the social, the animal and the spiritual, which constitutes a most profound structure of the humanity of the human. We are an animal which engages in the most sublime spiritual, intellectual and poetic practices, which worships gods and creates art, which splits atoms and theorizes big bangs, which votes 
and loves, which massacres children, which dies, which attests to values to which it cannot live up, and which has brown ooze and uncontrollable foul-smelling gusts of wind coming from a small hole in the back of it. This is all the stuff of comedy. We have to laugh at ourselves and each other. We are essentially paradoxical creatures. Our humanity manifests as complexes of reason and affect. And this attests to and explains the impotence of either-or debates over the politics of nature and culture to account for what we are. We are stranded. Heller's turn to the philosophical anthropologists of the 1920s attempts to give remedy to the aporetic situation in the study of the humanities at the end of the twentieth century, where decades of dominance of theories of social determinism which have reached the limits of their powers of explicability must be called into question. We are bodies, but not mere bodies, we are social, but not mere herds, we are rational, but not entirely so. And we live these "not only but also" gaps, these abysses, as a real, tangible, physical body with predeterminations, potentials, habits, stresses, vague impressions, buried functional affects and self-delusions of will and control. The hope of this study is that Heller's theory of laughter might provide not only explanation of the strange coughing judgment whose sharing heals us and brings us together, but may also point ways to broader new understandings in the limits and definitions of the question of what it means to be human.

\section{Brief Note on Pedagogical Outcomes}

This research occurred as a subject unit within a university program, and therefore needed to achieve certain pedagogical outcomes. Whilst this is not the appropriate venue to discuss in detail the efficacy of group phenomenological work as a pedagogical environment, with all the attendant theories of teaching and learning which such a study would need to consider, I think it 
is important, considering the outcomes which were achieved, to note that this is a future avenue for practical research projects which would not only make a significant contribution to educational practices and outcomes, but which would also carry forward the cause of practical phenomenology into an area where its greater social and human worth might be effectively revealed and utilized.

Whilst I conducted no concrete conclusive research into the efficacy of the various assessments in this first phase of the work, it was interesting to note that the students in the phenomenology group learned the concepts more quickly and could more effectively interpret comedic material through the prism of the theory than the other assessment groups. This took me by surprise. When the course runs again next year, we intend to conduct a parallel study employing techniques from phenomenological psychology, as pioneered by Amadeo Giorgi at Duquesne University, to qualitatively measure these processes and effects.

\section{Summary Findings}

The primary result of this first stage of the research was a series of more specific operators or protocols for further study. Whether these operators are the most fundamental transcendental categories of the comic, or whether they are true phenomenological essences is open to discussion, but they were certainly questions yielded by a sustained phenomenological reduction conducted in immersion with the phenomena. As such they stand as clarified material for further enquiry, which will hopefully aid the understanding of hidden dimensions of a misunderstood, fundamental human phenomenon. 
In Heller's terms, the questions are: How to make sayable this social/genetic abyss which emerges at this underlying transcendental level? How to thematize, bring to experience, or hesitate with the lightning fast, barely perceptible moments of the instinct of the rational as they emerge from and as the abyss of failed social/genetic dovetailing? How to stay with the moment, dilating it to allow its investigation?

A smaller, more focused group is currently addressing these topics: Speed, Timing and Temporality; Comic Catharsis-Embodied and Social; Structures of Evocation and Resonance; Intersubjective/Objective Intentional Descriptions; and Typologies of Laughter. Students are working on producing discussions and papers on each of these areas. Hopefully, in the spirit of Husserl's "infinite task" ("Philosophy and the Crisis"), our work will lead to further clarifications and more fundamental categories for further investigation, and we will be better able to understand this strange, lightning-fast judgment which manifests as a coughing spasm of the diaphragm and the larynx, and which somehow facilitates belonging and mutual understanding.

Moreover, as we progress in our work, we are becoming more convinced of the import of Heller's conception of the abyss between the social and the genetic aprioris as a fundamental structure of the human. If her contention holds, then to be human is to live this abyss, and to live this abyss is to live an ultimately irreconcilable tension for which "laughter is the best medicine." The acceptance of this premise of a definition grounded in originary paradox opens up infinite avenues for enquiry into the question of what it means to be human. Beginning with the excavation of the relation and role of laughter to the primordial abyss, we hope it may be possible to construct practical phenomenological approaches to shed light on other taken-forgranted, hidden and misunderstood human phenomena. 


\section{Notes}

${ }^{1}$ The concept of the genetic and social aprioris are central to Heller's theory of the comic, and to this project. They stem from the turn in her theory to the work of the German philosophical anthropologists of the 1920-40s. The history and definition of the terms is expanded as necessary as this essay continues. In her lectures, Heller gave the example of the human genetic need/capacity to belong to a group for its survival. We are a pack animal. However, this genetic potential must adapt to a specific pre-existent social order. The concept of dovetailing describes the adaptation of the genetic potential to the actual situation in which it finds itself. The contention is that this process never happens entirely successfully. Heller's use of the term genetic here is contentious, in that it used to denote behaviours and potentials in the human animal which, in the late twentieth century humanities, with their poststructuralist, feminist, perspectivist imperatives, have been generally understood to be socially determined. The work of the early Twentieth Century German philosophical anthropologists, particularly Arnold Gehlen, has been much maligned due to its usage in the context of Nazi eugenics. Heller revives it deliberately here in service of an emphasis on universal human essences. The assumption is that laughter is best approached as a universal human phenomenon.

2 The specific definition of the terms abyss and genetic and social a priori are given below in the sub-section, The Abyss and the Failure of Dovetailing.

3 The definitions of the types of reduction used in this paper are derived from Husserl's various drafts of the Encyclopaedia Britannica article, written in 1927. In these works, conducted partly under the pressure of a critique by Heidegger, Husserl makes numerous attempts to clarify the limits, workings, and intertwinings of the two primary levels of reduction-the psychological or worldly, and the transcendental — and also takes great pains to explain the eidetic nature of all reduction to an uninitiated audience.

${ }^{4}$ In our descriptions, we found that two of Heller's primary contentions-that the comic contains no element of tragedy, and that laughter is without empathy-to be questionable. There is sympathetic laughter which arises as the acknowledgment of another's misfortune. It appears that although the precise event of the eruption of the laugh is indicative of a judgment being made, the circumstances in which the judgment is made can be both tragic and empathetic. Current study is being given to the complex of relationships between tragic, empathetic and comic phenomena.

${ }^{5}$ In this, their inexperience was an advantage because they were not embedded in debates about terms, but were amenable to receive and act on instructions.

${ }^{6}$ A strong-tasting sandwich spread very popular in Australia-often cited as a national emblem.

${ }^{7}$ http://www.youtube.com/watch?v=4DFTmBrMYPw 
8 This joke form is so prevalent in our culture that we could nearly map its different manifestations to do a developmental psychology of the complexity of cognitive understandings in children of different ages.

${ }^{9}$ At present, a group of ten students are working in audiences and other comedic situations, conducting further reductions, taking different taken-for-granted assumptions out of play, in order to allow these categories to be explored.

${ }^{10}$ Anonymous PhaenEx reviewer.

\section{Works Cited}

Aristotle. Poetics 1, Part V. Trans. S. H. Butcher. The Internet Classics Archive, 1994-2000. 20 July 2008. <http://classics.mit.edu/Aristotle/poetics.1.1.html>.

Brentano, F. Psychology from an Empirical Standpoint. London: Routledge \& Kegan Paul, 1973.

Bergson, H. Laughter: An Essay on the Meaning of the Comic. Trans. Cloudesley Brereton \& Fred Rothwell. Project Gutenberg, Etext \#4352, August 2003. 20 July 2008. $<$ http://www.gutenberg.org/dirs/etext03/laemc10.txt>.

Casey, E. “Sym-Phenomenologizing: Talking Shop.” Human Studies 20, no. 2 (1997): 169-180.

Critchley, S. On Humour. London: Routledge, 2002.

Freud, S. "Wit and its relation to the unconscious." Complete Psychological Works, Vol 8. Trans. James Strachey. London: Hogarth Press, 1960.

Gehlen, A. Man: His Nature and Place in the World. Trans. Clare McMillan and Karl Pillemer. New York: Columbia University Press, 1988.

Giorgi, A. Psychology as a Human Science. NY: Harper \& Row, 1970.

Grant, S. "Practical Intersubjectivity." Janus Head 8, no. 2 (2005): 560-580. 21 July 2008. $<$ http://www.janushead.org/8-2/Grant.pdf>.

—. "Immanent Description and Writing From..." Pli: Warwick Journal of Philosophy 20 (2007): 59-82.

Gutwirth, M. Laughing Matter: an Essay on the Comic. Ithaca: Cornell UP, 1993. 
Heidegger, M. Being and Time. Oxford: Blackwell, 1962.

Heller, A. Immortal Comedy. Lanham, MD: Lexington Books, 2005.

Hobbes, T. The Elements of Natural Law and Politic. McMaster University. 27 July 2008. $<$ http://socserv.mcmaster.ca/econ/ugcm/3113/hobbes/elelaw $>$.

Husserl, E. “"Phenomenology,' Britannica Article, Fourth Draft (1927).” Stanford University. Trans. Richard Palmer. 28 July 2008. <http://www.stanford.edu/dept/relstud/faculty/sheehan.bak/EHtrans/8-eb.pdf>.

-. "Philosophy and the Crisis of European Man (Lecture delivered by Edmund Husserl, Vienna, 10 May 1935).” Trans. Quentin Lauer. 22 Sept 2008. $<$ http://www.users.cloud9.net/ bradmcc/husserl_philcris.html>.

Kant, I. The Critique of Judgement. Trans. James Creed Meredith. Philosophy Eserver. 27 July 2008. <http://philosophy.eserver.org/kant/critique-of-judgment.txt>.

Laughter Clubs Victoria. 27 July 2008. <http://www.laughterclubsvic.org>.

Melbourne International Comedy Festival. "Background." 26 July 2008. <http://www.comedyfestival.com.au/about/background/>.

Merleau-Ponty, M. Phenomenology of Perception. Trans. Colin Smith. New Jersey: The Humanities Press, 1962.

Morreall, J. “A New Theory of Laughter”. Philosophical Studies 42 (1982): 243-254.

—. The Philosophy of Laughter and Humour. Albany: SUNY Press, 1987.

Pete and Brian. "Knock-Knock.” 22 Sept 2008. http://www.youtube.com/watch?v=4DFTmBrMYPw

Pfeifer, K. "From Locus Neoclassicus to Locus Rattus: Notes on Laughter, Comprehensiveness and Titillation." Res Cogitans 3 (2006): 29-46.

Plato. Philebus. Trans. B. Jowett. Project Gutenberg, Etext \#1744. May, 1999. 20 July 2008. $<$ http://www.gutenberg.org/dirs/etext99/philb10.txt>.

Plessner, H. Laughing and Crying. Evanston: Northwestern University Press, 1970.

Provine, R. Laughter: A Scientific Study. New York: Viking, 2000. 
Prusak, B. "The science of laughter: Helmuth Plessner's laughing and crying revisited". Continental Philosophy Review 38 (2006): 41-69.

Sanders, B. Sudden Glory: Laughter as Subversive History. Boston: Beacon Press, 1995.

Schopenhauer, A. "From The World as Will and Idea," reprinted in Theories of Comedy. Ed. P. Lauter. New York: Anchor, 1964. 355-371.

Seamon, D. A Geography of the Lifeworld. London: Croom Helm, 1979.

Spiegelberg, H. Doing Phenomenology. The Hague: Martinus Nijhoff, 1975.

Steinbock, A. "Back to the Things Themselves." Human Studies 20 (1997): 127-135. 